\title{
High CMRR voltage mode instrumentation amplifier using a new CMOS differential difference current conveyor realization
}

\author{
T. Ettaghzouti, N. Hassen
}

\begin{abstract}
This paper describes a new CMOS realization of differential difference current conveyor circuit. The proposed design offers enhanced characteristics compared to DDCC circuits previously exhibited in the literature. It is characterized by a wide dynamic range with good accuracy thanks to use of adaptive biasing circuit instead of a constant bias current source as well as a wide bandwidth $(560 \mathrm{MHz})$ and a low parasitic resistance at terminal $\mathrm{X}$ about $6.86 \Omega$.

A voltage mode instrumentation amplifier circuit (VMIA) composed of a DDCC circuit and two active grounded resistances is shown as application. The proposed VMIA circuit is intended for high frequency applications. This configuration offers significant improvement in accuracy as compared to the state of the art. It is characterized by a controllable gain, a large dynamic range with THD less than $0.27 \%$, a low noise density $\left(22 \mathrm{nV} / \mathrm{Hz}^{1 / 2}\right)$ with a power consumption about $0.492 \mathrm{~mW}$ and a wide bandwidth nearly $83 \mathrm{MHz}$.

All proposed circuits are simulated by TSPICE using CMOS $0.18 \mu \mathrm{m}$ TSMC technology with $\pm 0.8 \mathrm{~V}$ supply voltage to verify the theoretical results.
\end{abstract}

Keywords-Differential difference current conveyor (DDCC), Adaptive biasing circuit, Instrumentation amplifier (IA), Voltage mode, CMRR.

\section{INTRODUCTION}

A $\mathrm{n}$ instrumentation amplifier is an important electronic device widely applied to amplify the small differential signals in the presence of large common-mode interference. This integrated circuit present a kind of differential amplifier family which can be found in medical instrumentation [1-5], readout circuits of biosensor [6,7], data acquisition and signal processing [8].

The first proposed instrumentation amplifier circuit is built of three operational amplifier integrated circuits and seven resistances. This circuit is characterized by major cons which are the limitations of the bandwidth and the common-mode rejection ratio (CMRR). To overcome these problems, novel

T. Ettaghzouti is assistant professor of Physic, microelectronics and electronics to Faculty of Arts and Sciences Al Qurayyat, Jouf University, Saudi Arabia (corresponding author to provide phone: +966557718089; email: thourayataghzouti@yahoo.fr tettaghzouti@ju.edu.sa).

N. HASSEN was professor of microelectronics and electronics to ISIMM University of Monastir, Tunisia (corresponding author to provide phone: +216 73464 168; e-mail: nejib.hassen@fsm.rnu.tn).. instrumentation amplifier topologies have introduced in the literature. In 2010, Erkan Yuce has proposed four instrumentation amplifier (IA) topologies, one of which is current-mode $(\mathrm{CM})$ while the others are voltage-mode (VM), using current feedback operational amplifiers (CFOAs) [9]. In 2013, a new design of a chopper current mode instrumentation amplifier composed by two second generation current conveyor circuits has presented. This circuit aims to be the reading circuit of a high precision temperature sensor [10]. In 2016, a new design of a current mode instrumentation amplifier (CMIA) based on the flipped voltage follower (FVF) is proposed [11].

In this paper, a high performance differential difference current conveyor circuit (DDCC) operated at $\pm 0.8 \mathrm{~V}$ is presented. Through the use of a modified flipped voltage follower cell as an adaptive biasing circuit and compensation impedances in form of a resistance in series with a capacitor, this circuit is characterized by a voltage dynamic range about $\pm 0.62 \mathrm{~V}$ with THD less than $0.25 \%$, a low parasitic impedance at terminal X (6.86 $\Omega$ ) and wide bandwidth about $558 \mathrm{MHz}$. Also, the current mode responses of DDCC circuit show a $\pm 0.35 \mathrm{~mA}$ dynamic range and a bandwidth about $560 \mathrm{MHz}$. The power consumption is about $0.472 \mathrm{~mW}$.

As an application, a controlled voltage mode instrumentation amplifier circuit using a DDCC circuit and two grounded active resistances is proposed. This circuit is intended for high frequency applications. It is characterized by controlled gain, wide bandwidth about $83 \mathrm{MHz}$, a high CMRR $(146 \mathrm{~dB})$ and power consumption about $0.492 \mathrm{~mW}$.

\section{ADAPTIVE BIASING}

Adaptive biasing circuit presents a typical solution very used in the modern applications to overcome the problem of the large bias current $[12,13]$. This circuit is characterized by a high input impedance, a low output resistance, high precision currents and the possibility to operate with a lower voltage supply.

The schematic diagram of differential pair polarized by adaptive biasing circuit $[14,15]$ is presented in Fig. 1. This technique allows to couple the differential pair by two DC voltage level shifters. 


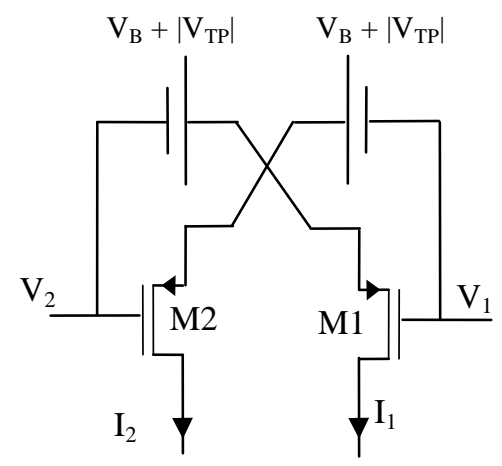

Fig. 1 Schematic diagram of differential pair biased by adaptive biasing circuit

The current drain expression of differential pair operating in saturation mode is given by:

$$
I_{1,2}=\frac{\beta_{1,2}}{2}\left(V_{S G 1,2}-\left|V_{T P}\right|\right)^{2}
$$

Assuming that the transistors M1-M2 are identical, the differential output current $\left(\mathrm{I}_{\mathrm{d}}\right)$ is defined as:

$$
I_{d}=I_{1}-I_{2}=\frac{\beta_{1,2}}{2}\left(V_{S G 1}+V_{S G 2}-2\left|V_{T P}\right|\right)\left(V_{S G 1}-V_{S G 2}\right)
$$

In order to obtain a linear differential current $\left(\mathrm{I}_{\mathrm{d}}\right)$, the term $\mathrm{V}_{\mathrm{SG} 1}+\mathrm{V}_{\mathrm{SG} 2}-2\left|\mathrm{~V}_{\mathrm{TP}}\right|$ must have a constant value. As solution, two floating $D C$ voltage sources with values $V_{B}-\left|V_{T P}\right|$ have been integrated, as shown in Fig 1.

The sum and difference relationships between $\mathrm{V}_{\mathrm{SG} 1}$ and $\mathrm{V}_{\mathrm{SG} 2}$ are given by:

$$
\begin{aligned}
& V_{S G 1}+V_{S G 2}=2\left(V_{B}+\left|V_{T P}\right|\right) \\
& V_{S G 1}-V_{S G 2}=2\left(V_{1}-V_{2}\right)
\end{aligned}
$$

The differential output current expression has become:

$$
I_{d}=2 \beta V_{B}\left(V_{1}-V_{2}\right)=g_{m}\left(V_{1}-V_{2}\right)
$$

The linear input signal range and the linear output signal range are delimited respectively by:

$$
\begin{gathered}
\left|V_{1}-V_{2}\right|<V_{B} \\
I_{d}<2 \beta V_{B}^{2}
\end{gathered}
$$

Fig. 2 shows different CMOS source follower topologies. The common drain amplifier is presented in Fig 2 (a). It presents the simplest design of a high linearity unity buffer [16]. This circuit can be operated with a minimum supply voltage of :

$$
V_{D D, \min }-V_{\mathrm{ss}, \min }=V_{S D 1, \text { sat }}+V_{S D 2, \text { sat }}
$$

Also, this circuit can be used as a voltage follower where the output voltage follows the input voltage with a DC level shift $\left(\mathrm{V}_{\mathrm{SG} 1}\right)$.

$$
V_{\text {OUT }}=V_{I N}+V_{S G 1}
$$

Regarding behavior of large-signal, this circuit is capable to sink a large current from the load, but its sourcing capability is limited by the current drain of transistor M2. The major disadvantage of this circuit is that the current through the transistor M1 depends on the output current. Consequently, the voltage gain is less than unity.

The voltage gain and the output resistance expressions are given by:

$$
\begin{aligned}
\frac{V_{\text {OUT }}}{V_{I N}} & =\frac{r_{o 1} r_{o 2} g_{m 1}}{r_{o 1}+r_{o 2}+r_{o 1} r_{o 2} g_{m 1}} \\
R_{\text {OUT }} & =\frac{r_{o 1} r_{o 2}}{r_{o 1}+r_{o 2}}
\end{aligned}
$$

The circuit shown in Fig 2 (b) presents a modified voltage follower circuit named flipped voltage follower (FVF) [17, 18]. The current through transistor M1 is kept constant, regardless of the output current, thanks to the use of transistor M3 as a source of bias current. Considering that the shortchannel effect $\mathrm{V}_{\mathrm{SG}, \mathrm{M} 1}$ held constant, the voltage gain is unity. Contrary to the classic voltage follower, this circuit is able to source a large amount of current. But, its damping capability is limited by the current through the transistor M1. The large sourcing capability is due to the low impedance at the output node.

The voltage gain and the output resistance expressions are given by:

$$
\begin{aligned}
& \frac{V_{\text {OUT }}}{V_{I N}}=\frac{r_{o 1} r_{o 2} r_{o 3} g_{m 1} g_{m 2}}{r_{o 2}+r_{o 2} r_{o 3} g_{m 2}+r_{o 1} r_{o 2} g_{m 1}+r_{o 1} r_{o 2} r_{o 3} g_{m 1} g_{m 2}} \\
& R_{O U T}=\frac{r_{o 1} r_{o 2}+r_{o 2} r_{o 3}}{r_{o 1}+r_{o 2}+r_{o 3}+r_{o 1} r_{o 2} r_{o 3} g_{m 1} g_{m 2}}
\end{aligned}
$$

The minimum supply voltage used to power FVF circuit is expressed by:

$$
V_{D D, \text { min }}-V_{S S, \text { min }}=V_{S D_{M 3}, s a t}+V_{S D_{M 2}, \text { sat }}+\left|V_{T P 2}\right|
$$

The linear operation region of FVF circuit is still valid for transistors M1 and/or M2 operated in saturation region. The valid region of limited common mode input voltage range is expressed by:

$$
V_{S S}+V_{D S_{M}, \text { sat }}-\left|V_{T P 1}\right|<\mathrm{V}_{C M}<\mathrm{V}_{\mathrm{DD}}-\mathrm{V}_{\mathrm{SD}_{\mathrm{M} 2} \text {, sat }}-\mathrm{V}_{\mathrm{SD}_{\mathrm{M} 1}, \text { sat }}-\left|V_{T P 1}\right|
$$

The folded flipped voltage follower (FFVF) presented in Fig 2 (c) is introduced as a solution for the limited current delivering capability of FVF [19]. The transistor M4 provides additional current whenever it is required by load. Therefore, this circuit is capable to sink and provide large current. The voltage gain and the output resistance expressions are given by:

$$
\begin{aligned}
& \frac{V_{\text {OUT }}}{V_{I N}}=\frac{r_{o 1} r_{o 2} r_{o 3} r_{o 4} g_{m 1}\left(g_{m 2}+g_{m 4}\right)}{\left(r_{o 1}+r_{o 3}\right)\left(r_{o 4}+r_{o 2}\right)+r_{o 1} r_{o 2} r_{o 3} r_{o 4} g_{m 1}\left(g_{m 2}+g_{m 4}\right)} \\
& R_{\text {OUT }}=\frac{r_{o 2} r_{o 4}\left(r_{o 1}+r_{o 3}\right)}{\left(r_{o 1}+r_{o 3}\right)\left(r_{o 4}+r_{o 2}\right)+r_{o 1} r_{o 2} r_{o 3} r_{o 4} g_{m 1}\left(g_{m 2}+g_{m 4}\right)}
\end{aligned}
$$

The minimum supply voltage used to power FFVF circuit is expressed by:

$$
V_{D D, \text { min }}-V_{S S \text {, min }}=V_{S D_{M 2} \text {, sat }}+V_{D S_{M 4}, \text { sat }}+\left|V_{T P 2}\right|+\left|V_{T P 4}\right|
$$




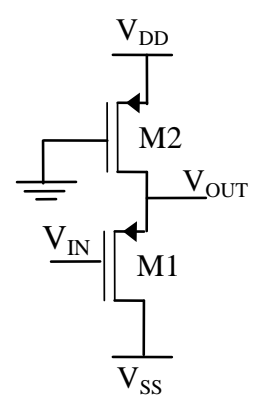

(a)

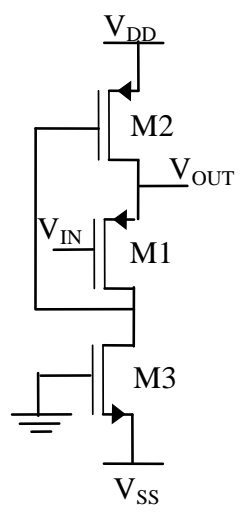

(b)

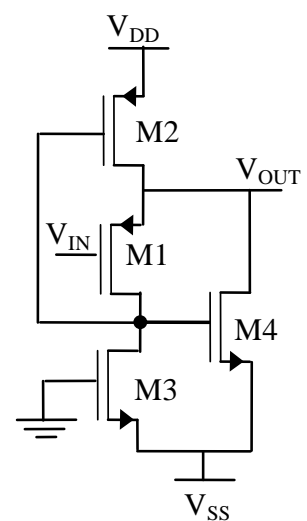

(c)

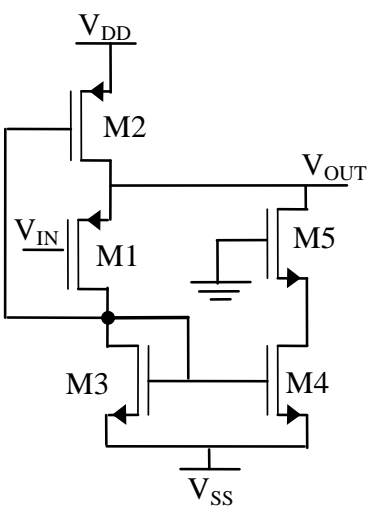

(d)

Fig 2 Voltage buffer: (a) common-drain, (b) Flipped voltage follower (c) Folded flipped voltage follower, (d) Modified folded flipped voltage follower

The valid region of limited common mode input voltage range is expressed by:

$V_{S S}+V_{D S_{M 4}, \text { sat }}+\left|V_{T P 4}\right|-\left|V_{T P 1}\right|<\mathrm{V}_{C M}<\mathrm{V}_{\mathrm{DD}}-\mathrm{V}_{\mathrm{SD}_{\mathrm{M} 2}, \mathrm{sat}}-\mathrm{V}_{\mathrm{SD}_{\mathrm{M} 1}, \mathrm{sat}}-\left|V_{T P 1}\right|$

The modified folded flipped voltage follower (FFVF) is presented in Fig. 2 (d). The transistor M5 has been integrated in order to minimize the output impedance. The voltage gain and the output resistance expressions are given by:

$$
\begin{gathered}
\frac{V_{\text {OUT }}}{V_{I N}}=\frac{r_{o 2} r_{o 4} r_{o 5} g_{m 1} g_{m 3} g_{m 4} g_{m 5}}{r_{02} r_{o 4} r_{o 5} g_{m 1} g_{m 3} g_{m 5}\left(g_{m 3}+g_{m 2}\right)} \\
+r_{o 5} r_{o 4} g_{m 3} g_{m 5}\left(g_{o 4}+r_{o 5} g_{m 1} g_{m 4} g_{m 5}\right) \\
R_{\text {OUT }}= \\
\begin{array}{c}
\left.r_{o 4} r_{o 5} g_{m 5}\left(g_{m 3}+g_{m 2}\right)\right) \\
+r_{o 1} g_{m 3}\left(g_{m 3}+r_{o 4} r_{o 5} g_{m 2} g_{m 4} g_{m 5}\right)
\end{array}
\end{gathered}
$$

The characteristics for all voltage follower circuits have been estimated by TSPICE using $0.18 \mu \mathrm{m}$ CMOS TSMC with $\pm 0.8 \mathrm{~V}$ supply voltage. The variations of output voltage according to the variation of input voltage show the same linear behavior over an input voltage range from $-0.8 \mathrm{~V}$ to $0.45 \mathrm{~V}$, as presented in Fig. 3.

From Fig. 4, it can be noticed that, the output impedance of modified folded flipped voltage follower at low frequency is less than those of flipped FVF, conventional FVF and common drain amplifier. The output impedances present resistive behaviors equal respectively to $170 \Omega, 461.2 \Omega, 873.9 \Omega$ and $4.52 \mathrm{k} \Omega$ up to $0.6 \mathrm{GHz}$.

\section{DIFFERENTIAL DIFFERENCE CURRENT CONVEYOR CIRCUIT DDCC}

\section{A. Circuit description}

The differential difference current conveyor circuit was introduced as new active building block in 1996 by W. Chiu et al [20]. This circuit has three voltage input terminals (Y1, Y2, Y3) with high impedances, a current input terminal (X) with a low impedance and a current output terminal $(Z)$ with a high impedance. The relationships between voltage and current terminals can be expressed in the real case by the following matrix equation.

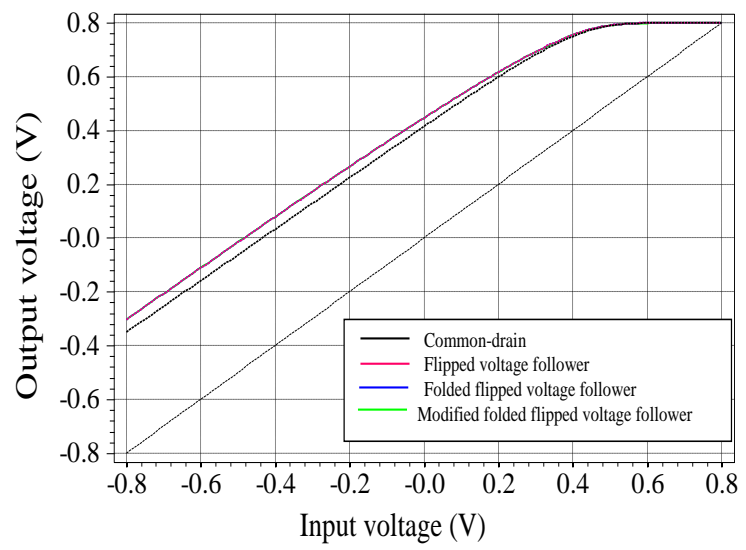

Fig. 3 DC voltage transfer characteristics

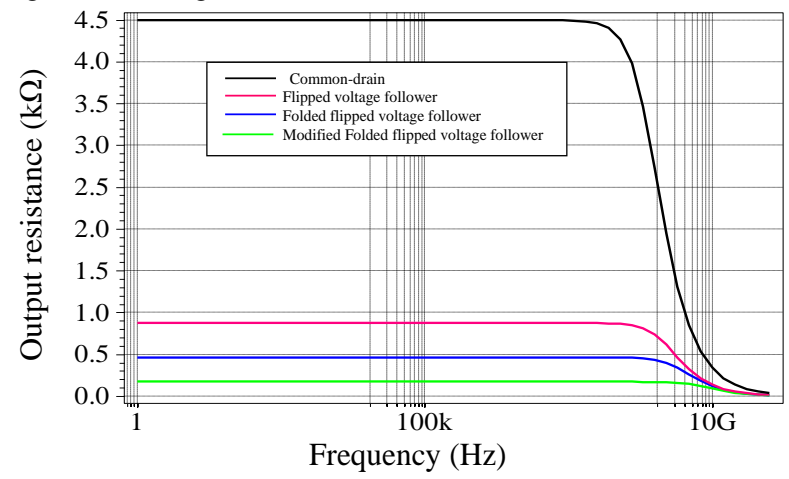

Fig 4 Variation of output impedances according to frequency

where $\beta_{\mathrm{j}}=1-\varepsilon v \mathrm{j}$ for $(\mathrm{j}=1,2,3)$ and $\alpha=1-\varepsilon_{\mathrm{i}}$, whereas $\varepsilon_{\mathrm{vj}}$ and $\varepsilon_{\mathrm{i}}\left(\left|\varepsilon_{\mathrm{vj}}\right|<<1\right.$ and $\left.\left|\varepsilon_{\mathrm{i}}\right|<<1\right)$ represent voltage and current tracking errors of circuit, respectively. There are two types of DDCC depending on the sign of $\alpha$, namely positive-type (DDCC+) or negative-type (DDCC-). 


$$
\left[\begin{array}{l}
I_{Y 1} \\
I_{Y 2} \\
I_{Y 3} \\
V_{X} \\
I_{Z}
\end{array}\right]=\left[\begin{array}{ccccc}
0 & 0 & 0 & 0 & 0 \\
0 & 0 & 0 & 0 & 0 \\
0 & 0 & 0 & 0 & 0 \\
\beta_{1} & -\beta_{2} & \beta_{3} & 0 & 0 \\
0 & 0 & 0 & \pm \alpha & 0
\end{array}\right]\left[\begin{array}{c}
V_{Y 1} \\
V_{Y 2} \\
V_{Y 3} \\
I_{X} \\
V_{Z}
\end{array}\right]
$$

The overall CMOS circuit of proposed DDCII is shown in Fig. 5. The input stage is composed by two PMOS differential pairs (M1, M2) and (M3, M4) biased by two adaptive biasing circuits, composed by CMOS source follower shown in Fig. 3 (d), and three current mirrors (M5, M6), (M7, M8) as well as (M9, M10) such as the drains of M6 and M8 are connected respectively to M9 and M10.

The offset voltage expression between the input voltages $\left(\mathrm{V}_{\mathrm{Y} 1}, \mathrm{~V}_{\mathrm{Y} 2}, \mathrm{~V}_{\mathrm{Y} 3}\right)$ and the output voltage $\left(\mathrm{V}_{\mathrm{X}}\right)$ is given by:

$$
\begin{aligned}
\Delta V & =V_{X}-\left(V_{Y 1}-V_{Y 2}+V_{Y 3}\right) \\
& \approx \lambda_{p}\left[V_{D 1-3}\left(\sqrt{\frac{2 I_{1}}{\beta_{1}}}-\sqrt{\frac{2 I_{3}}{\beta_{3}}}\right)-V_{D 2-4}\left(\sqrt{\frac{2 I_{2}}{\beta_{2}}}-\sqrt{\frac{2 I_{4}}{\beta_{4}}}\right)\right]
\end{aligned}
$$

where, $V_{D 1-4}$ and $I_{1-4}$ are the drain voltages and the drain currents of transistors M1-M4.

It is clear that the offset voltage is null because the two pair differentials M1-M2 and M3-M4 have the same characteristics and the sum of drain currents $I_{1}+I_{3}$ and $I_{2}+I_{4}$ are equal since the drain terminals of transistors M6 and M8 are connected respectively to the drain terminals of transistors M9 and M10. Therefore, the first property of DDCC circuit is verified.

$$
V_{X}=V_{Y 1}-V_{Y 2}+V_{Y 3}
$$

The output stage composed of transistors M11 to M20 is constituted by two current mirrors and two offset adjustments. The current mirror M12-M15 has the same current drain than the two current mirrors M5-M6 and M7-M8 since the drain terminal of transistor M11 is connected to the drain terminal of transistor M13. Moreover, the connection of two drain terminals of transistors M14 and M15 respectively to the drain terminals of transistors M17 and M18 check the second property of the DDCC circuit.

$$
\mathrm{I}_{\mathrm{X}}=\mathrm{I}_{\mathrm{Z}}
$$

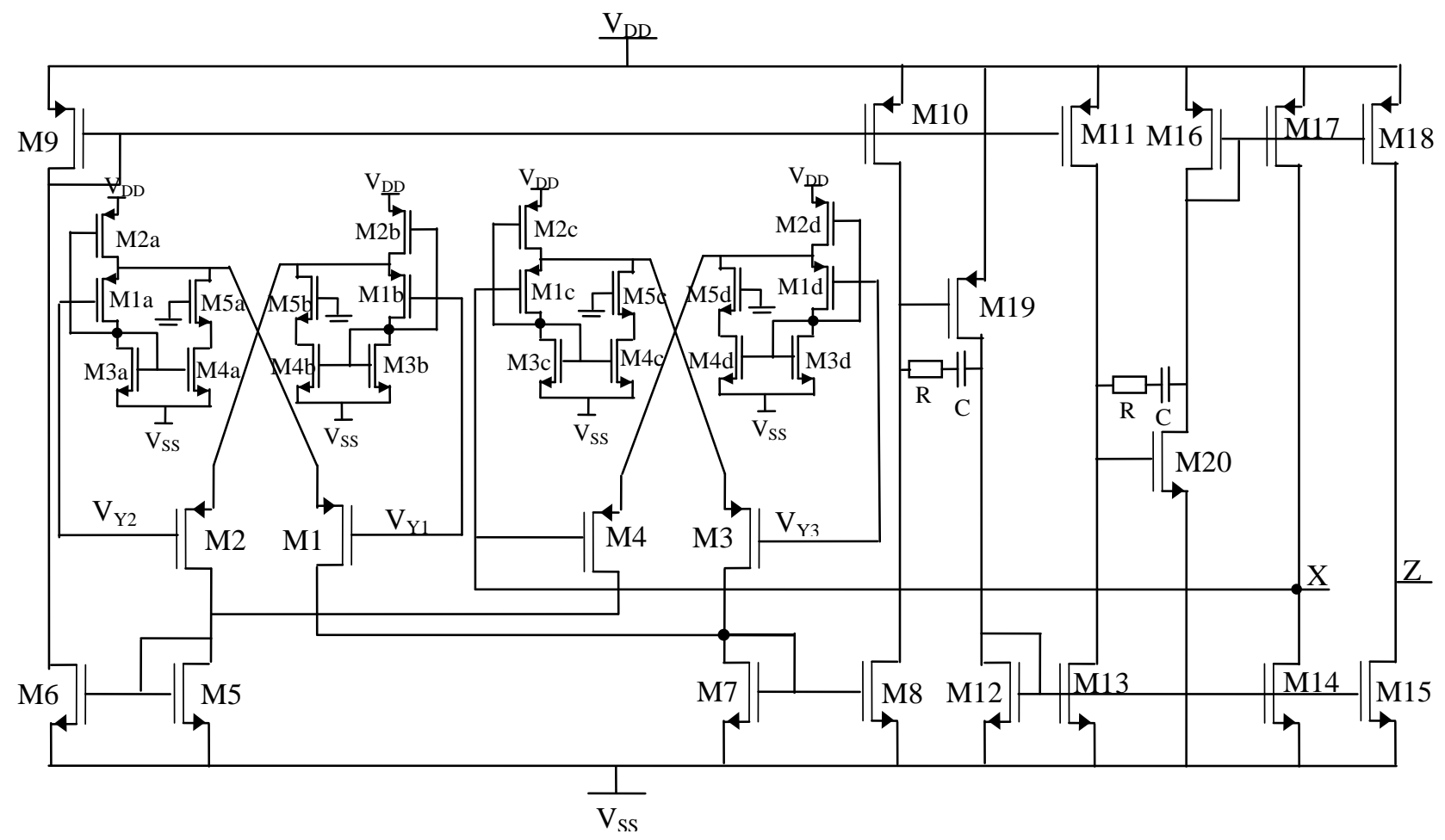

Fig 5. Proposed differential difference current conveyor circuit (DDCC)

According to the small-signal equivalent circuit analysis, the expressions of $\beta \mathrm{j}$ are given as following, while taking into account that the transistors of NMOS and PMOS current mirrors are characterized by same trans-conductance $\left(\mathrm{g}_{\mathrm{mN}}\right.$, $\left.\mathrm{g}_{\mathrm{mP}}\right)$ and same resistor seen at the drain of transistor $\left(\mathrm{r}_{\mathrm{N}}, \mathrm{r}_{\mathrm{P}}\right)$.

$$
\beta_{1}=\frac{V_{X}}{V_{Y 1}}=\frac{r_{N}^{3} \mathrm{r}_{P}^{3} g_{m P} g_{m N}\left(g_{m 2}+g_{m 1}\right)}{\left(r_{\mathrm{P}}+\mathrm{r}_{N}\right)^{3}+r_{N}^{3} \mathrm{r}_{P}^{3} g_{m P} g_{m N}\left(g_{m 2}+g_{m 1}\right)} \approx 1
$$

$$
\begin{aligned}
& \beta_{2}=\frac{V_{X}}{V_{Y 2}}=-\frac{r_{N}^{3} \mathrm{r}_{P}^{3} g_{m P} g_{m N}\left(g_{m 4}+g_{m 3}\right)}{\left(r_{\mathrm{P}}+\mathrm{r}_{N}\right)^{3}+r_{N}^{3} \mathrm{r}_{P}^{3} g_{m P} g_{m N}\left(g_{m 4}+g_{m 3}\right)} \approx-1 \\
& \beta_{3}=\frac{V_{X}}{V_{Y 3}}=\frac{r_{N}^{3} \mathrm{r}_{P}^{3} g_{m P} g_{m N}\left(g_{m 4}+g_{m 3}\right)}{\left(r_{\mathrm{P}}+\mathrm{r}_{N}\right)^{3}+r_{N}^{3} \mathrm{r}_{P}^{3} g_{m P} g_{m N}\left(g_{m 4}+g_{m 3}\right)} \approx 1
\end{aligned}
$$

The current transfer ratio $\alpha$ is equal to:

$$
\alpha \approx 1
$$


The parasitic resistance of the $\mathrm{X}$ terminal is given by:

$$
R_{X}=\frac{V_{X}}{I_{X}}=\frac{r_{N} r_{P}\left(r_{N}+r_{P}\right)^{2}}{\left(r_{N}+r_{P}\right)^{3}+r_{N}^{3} \mathrm{r}_{P}^{3} g_{m N}\left(g_{m P} g_{m 4}+g_{m N} g_{m 3}\right)}
$$

In order to stabilize the bandwidth of proposed DDCC circuit, compensation impedances in form of a resistance $\mathrm{R}$ in series with a capacitor $\mathrm{C}$ have been integrated as presented in Fig. 5. By considering the compensation impedances, the voltage transfer expression of proposed DDCC circuit is characterized by seven poles $\left(\omega_{\mathrm{p} 1-7}\right)$ and seven zeros $\left(\omega_{\mathrm{z} 1-7}\right)$, as given by:

$$
A_{V}=\frac{V_{X}}{V_{Y 1}-V_{Y 2}+V_{Y 3}}=A_{0} \frac{\left(1+\frac{s}{\omega_{z 1}}\right)\left(1+\frac{s}{\omega_{z 2}}\right) \ldots \ldots .\left(1+\frac{s}{\omega_{z 7}}\right)}{\left(1+\frac{s}{\omega_{p 1}}\right)\left(1+\frac{s}{\omega_{p 2}}\right) \ldots . .\left(1+\frac{s}{\omega_{p 7}}\right)}
$$

By substituting $s=j \omega$ and at $\omega=\omega_{\mathrm{H}}$, the squared magnitude of transfer function is given by:

$$
\left|A_{V}\left(j \omega_{H}\right)\right|^{2}=\frac{\left(1+\frac{\omega_{H}^{2}}{\omega_{z 1}^{2}}\right)\left(1+\frac{\omega_{H}^{2}}{\omega_{z 2}^{2}}\right) \ldots \ldots\left(1+\frac{\omega_{H}^{2}}{\omega_{z 7}^{2}}\right)}{\left(1+\frac{\omega_{H}^{2}}{\omega_{p 1}^{2}}\right)\left(1+\frac{\omega_{H}^{2}}{\omega_{p 2}^{2}}\right) \ldots \ldots\left(1+\frac{\omega_{H}^{2}}{\omega_{p 7}^{2}}\right)}=\frac{1}{2}
$$

The expression of $\omega_{\mathrm{H}}$ can be given by [21, 22]:

$$
\omega_{H} \cong \frac{1}{\sqrt{\left(\frac{1}{\omega_{p 1}^{2}}+\frac{1}{\omega_{p 2}^{2}}+\ldots . \frac{1}{\omega_{p 7}^{2}}\right)-2\left(\frac{1}{\omega_{z 1}^{2}}+\frac{1}{\omega_{z 2}^{2}}+\ldots . . \frac{1}{\omega_{z 7}^{2}}\right)}}
$$

By considering these approximations $\left(\omega_{\mathrm{p} 1}<<\omega_{\mathrm{p} 2}<<\ldots \omega_{\mathrm{p} 7}\right.$ and $\left.\omega_{\mathrm{p} 1}<<\omega_{\mathrm{z} 1}<<\omega_{\mathrm{z} 2} \ldots<<\omega_{\mathrm{z} 7}\right)$, the cut-off frequency of proposed differential difference current conveyor DDCC is roughly equal to the cut-off frequency of the first pole.

$$
f_{H}=f_{p 1}=\frac{2 r_{N}^{3} r_{P}^{3} g_{m N}^{3}}{2 \pi\left(\left(5 R r_{P}+5 R r_{N}+3 r_{N} r_{P}\right)\left(r_{N}+r_{P}\right)^{2}+14 r_{N}^{3} r_{P}^{3} g_{m N}^{3} R\right) C}
$$

\section{B. Simulation results}

The performance of the proposed DDCC circuit was verified by performing TSPICE simulations with supply voltages $\pm 0.8 \mathrm{~V}$ using $0.18 \mu \mathrm{m}$ TSMC CMOS technology. The transistor aspect ratios are given in Table 1 .

Table 1. Transistor aspect ratios of proposed DDCC circuit

\begin{tabular}{|c|c|}
\hline Transistor & $\boldsymbol{W}(\boldsymbol{\mu m}) / \mathbf{L}(\boldsymbol{\mu m})$ \\
\hline M1, M2, M3, M4 & $5 / 0.18$ \\
\hline M5, M6, M7, M8, M12, M13, M14, M15, & $3 / 0.18$ \\
\hline M20 & \\
\hline M9, M10, M11, M16, M17, M18, M19 & $10 / 0.18$ \\
\hline M1a, M1b, M1c, M1d & $2 / 0.18$ \\
\hline M2a, M2b, M2c, M2d & $40 / 0.18$ \\
\hline M3a, M3b, M3c, M3d, M4a, M4b, M4c, & $0.27 / 0.3$ \\
\hline M4d & $0.4 / 0.18$ \\
\hline M5a, M5b, M5c, M5d & \\
\hline
\end{tabular}

The DC voltage characteristics between Y-terminals and Xterminal are presented in Fig. 6. The output voltages obtained to $\mathrm{X}$-terminal according to $\mathrm{V}_{\mathrm{Y} 1}-\mathrm{V}_{\mathrm{Y} 2}+\mathrm{V}_{\mathrm{Y} 3}$ show a common dynamic range extended from $-0.62 \mathrm{~V}$ to $0.62 \mathrm{~V}$ with offset voltage less than $12 \mu \mathrm{V}$. The variation of output current $I_{Z}$ versus the current $I_{X}$ is shown in Fig. 7. With grounded $Y$ terminals and a load resistance of about $1 \mathrm{k} \Omega$, the current follower characteristic presents a maximum offset current of $12.2 \mathrm{nA}$ with the boundary linear range from $-350 \mu \mathrm{A}$ to $350 \mu \mathrm{A}$.

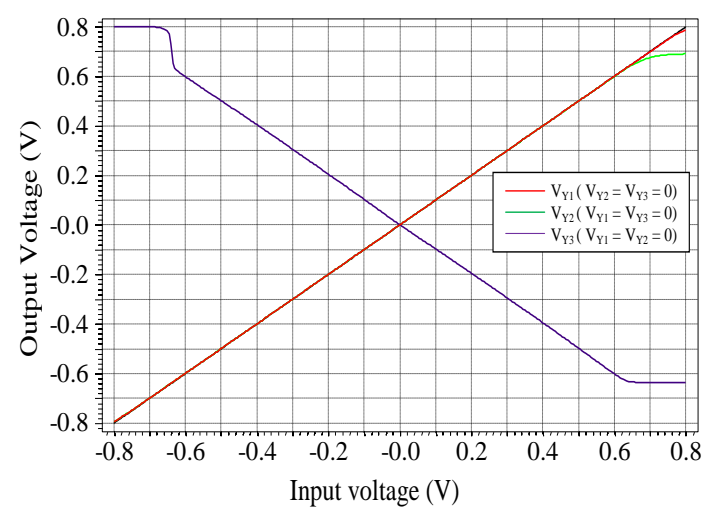

Fig. 6 DC transfer characteristic for voltage transfer

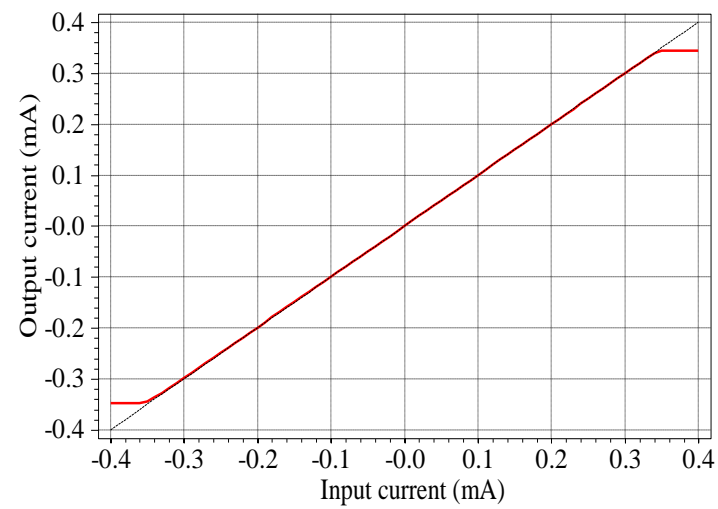

Fig. 7 DC transfer characteristic for current transfer

The frequency response of voltage gains $\left(\mathrm{V}_{\mathrm{X}} / \mathrm{V}_{\mathrm{Y} 1}, \mathrm{~V}_{\mathrm{X}} / \mathrm{V}_{\mathrm{Y} 2}\right.$, $\left.\mathrm{V}_{\mathrm{X}} / \mathrm{V}_{\mathrm{Y} 3}\right)$ and current gain $\left(\mathrm{I}_{\mathrm{Z}} / \mathrm{I}_{\mathrm{X}}\right)$ are plotted in Fig. 8. The cutoff frequencies of the voltage gains obtained without load are about $558 \mathrm{MHz}$ and unity gains at low frequencies. The frequency response of current gain shows a unit gain and a cutoff frequency about $563 \mathrm{MHz}$ with load resistance about $1 \mathrm{k} \Omega$. The frequency characteristic of parasitic impedance at $X$ terminal are presented in Fig 9. This circuit shows a resistive behaviors about $6.86 \Omega$ up to $10 \mathrm{MHz}$. The power consumption of DDCC circuit is about $472 \mu \mathrm{W}$.

Fig. 9 shows the variations of total harmonic distortion of output voltage $\mathrm{V}_{\mathrm{X}}$ for different peak to peak differential input voltage amplitudes with $10 \mathrm{kHz}$ and $1 \mathrm{MHz}$ frequency. 


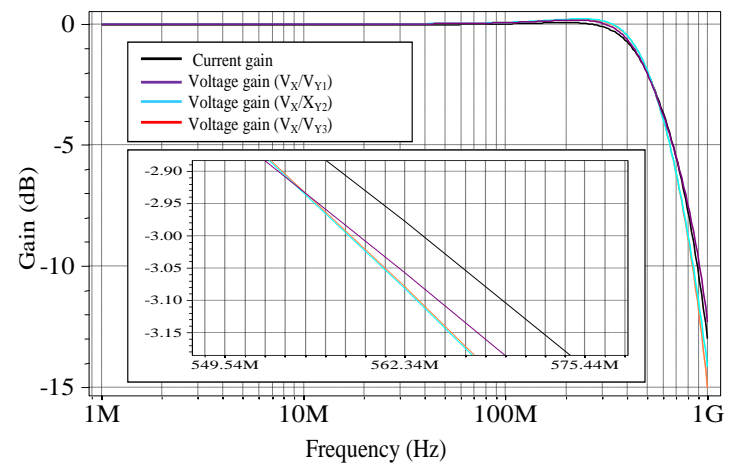

Fig. 8 Frequency responses of current and voltage gains

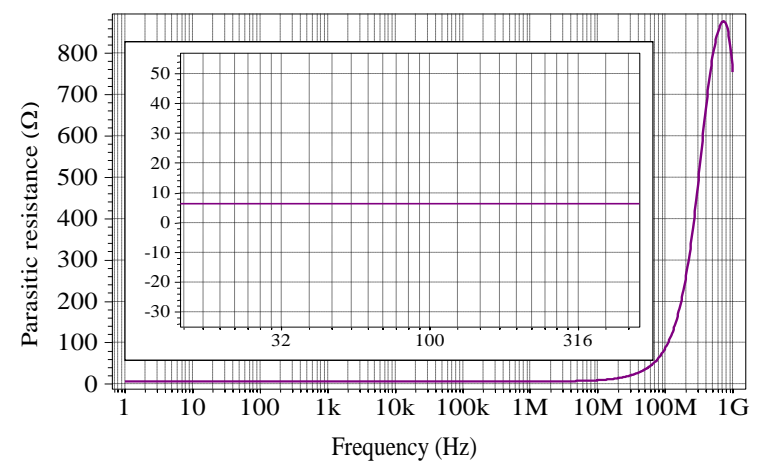

Fig. 9. Frequency response of parasitic impedance $Z_{X}$

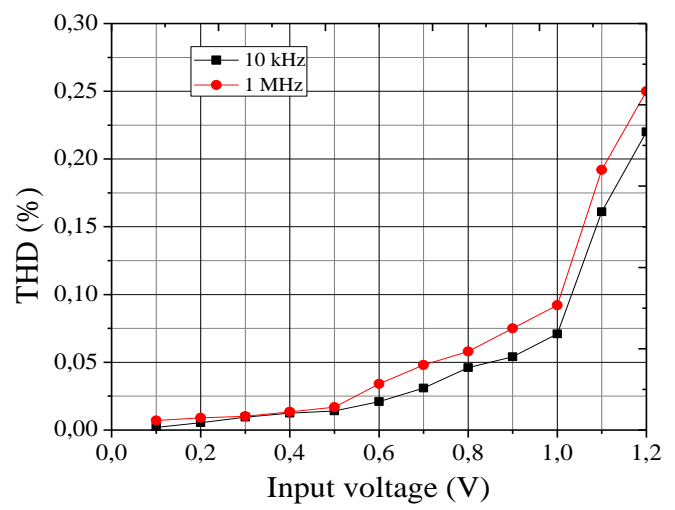

Fig. $10 \mathrm{THD}$ of voltage follower with $10 \mathrm{kHz}$ and $1 \mathrm{MHz}$.

Table 2 shows an impartial comparison between the proposed DDCC circuit and other proposed in the literature. it's obvious that our circuit is characterized by a large dynamic range, good accuracy as well as low parasitic resistance at Xterminal.

IV. Controlled voltage mode instrumentation amplifier (VMIA)

\section{A. Circuit Description}

The schematic diagram for proposed voltage mode instrumentation amplifier circuit is presented in Fig 11. It is composed of one differential difference current conveyor circuit (DDCC) and two grounded resistances.

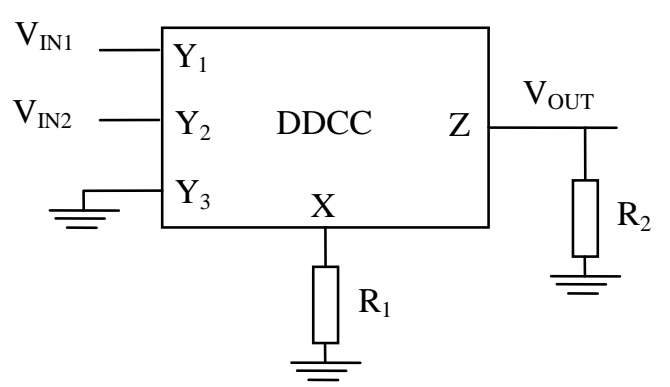

Fig. 11 Voltage mode instrumentation amplifier circuit (VMIA)

Considering the ideal case for DDCC circuit, the routine analysis yields the following transfer function:

$$
V_{\text {OUT }}=A_{0}\left(V_{I N 1}-V_{I N 2}\right)
$$

where, the gain $A_{0}$ is equal to the ratio $R_{2} / R_{1}$.

Taking into account the non-ideal gains of DDCC circuit, Eq (35) has become:

$$
V_{\text {OUT }}=\alpha A_{0}\left(\beta_{1} V_{I N 1}-\beta_{2} V_{I N 2}\right)
$$

From this expression, the differential-mode gain (ADM) and the common-mode gain (ACM) are respectively given by:

$$
\begin{aligned}
& A_{D M}=\frac{\alpha}{2} A_{0}\left(\beta_{1}+\beta_{2}\right) \\
& A_{C M}=\alpha A_{0}\left(\beta_{1}-\beta_{2}\right)
\end{aligned}
$$

The common-mode rejection ratio $\mathrm{CMRR}$ is computed as follows:

$$
C M R R=\left|\frac{A_{D M}}{A_{C M}}\right|=\frac{1}{2}\left|\frac{\beta_{1}+\beta_{2}}{\beta_{1}-\beta_{2}}\right|
$$

It is clear from this expression that the CMRR is independent of gain, which is a desired situation. The active and passive element sensitivities are evaluated as:

$$
\begin{gathered}
S_{V_{\text {OUT }}}^{A_{0}}=1 \quad S_{V_{\text {OUT }}}^{V_{I N 1}}=\frac{V_{I N 1}}{V_{I N 1}-V_{I N 2}} \quad S_{V_{\text {OUT }}}^{V_{I N 2}}=\frac{V_{I N 2}}{V_{I N 2}-V_{I N 1}} \\
S_{V_{\text {OUT }}}^{\alpha}=1 \quad S_{V_{\text {OUT }}}^{\beta_{1}}=\frac{\beta_{1} V_{I N 1}}{\beta_{1} V_{I N 1}-\beta_{2} V_{I N 2}} \quad S_{V_{\text {OUT }}}^{V_{I N 2}}=\frac{\beta_{2} V_{I N 2}}{\beta_{2} V_{I N 2}-\beta_{1} V_{I N 1}}
\end{gathered}
$$

The presences of parasitic impedances include effects not only on the gain but also on the value of the bandwidth. The proposed VMIA circuit considering the present of parasitic elements is shown in Fig. 12.

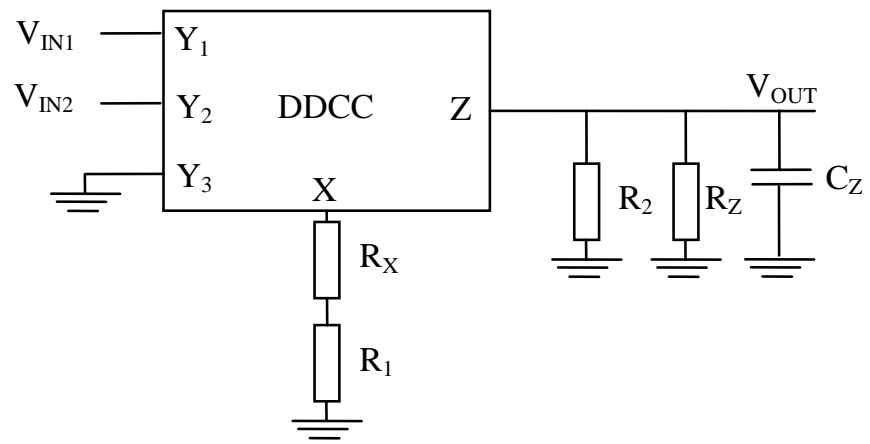

Fig 12 Instrumentation amplifier circuit considering the present of parasitic elements 
Table 2. Performance parameters comparison of proposed DDCC circuit with other reported in the literature

\begin{tabular}{|c|c|c|c|c|c|c|c|c|}
\hline & & \multicolumn{7}{|c|}{ Differential difference current conveyor DDCC } \\
\hline Parameters & Units & $\begin{array}{l}{[23]} \\
2012\end{array}$ & $\begin{array}{l}{[24]} \\
2013\end{array}$ & $\begin{array}{l}{[25]} \\
2010\end{array}$ & $\begin{array}{l}{[26]} \\
2010\end{array}$ & $\begin{array}{l}{[27]} \\
2016\end{array}$ & $\begin{array}{l}{[28]} \\
2011\end{array}$ & $\begin{array}{c}\text { Proposed } \\
\text { circuit }\end{array}$ \\
\hline Technology CMOS & $\mu \mathrm{m}$ & 0.18 & 0.18 & 0.25 & 0.25 & 0.25 & 0.25 & 0.18 \\
\hline Supply voltage & $\mathrm{V}$ & \pm 0.9 & \pm 0.3 & \pm 1.5 & \pm 1.5 & \pm 1.25 & \pm 1.25 & \pm 0.8 \\
\hline DC voltage range & V & --- & \pm 0.15 & \pm 0.9 & $\begin{array}{c}-- \\
--\end{array}$ & --- & \pm 0.3 & \pm 0.62 \\
\hline Voltage offset & $\mathrm{mV}$ & --- & $<0.093$ & 1.36 & --- & --- & --- & 0.012 \\
\hline $\begin{array}{l}\text { Bandwidth of voltage } \\
\text { transfer gain } \mathrm{V}_{\mathrm{X}} / \mathrm{V}_{\mathrm{Y} 1} \text {, } \\
\mathrm{V}_{\mathrm{X}} / \mathrm{V}_{\mathrm{Y} 2}, \mathrm{~V}_{\mathrm{X}} / \mathrm{V}_{\mathrm{Y} 3}\end{array}$ & $\mathrm{MHz}$ & $\begin{array}{c}588.84 \\
--- \\
--- \\
\end{array}$ & $\begin{array}{l}27 \\
--- \\
---\end{array}$ & $\begin{array}{c}120 \\
--- \\
--- \\
\end{array}$ & $\begin{array}{l}80 \\
--- \\
---\end{array}$ & $\begin{array}{r}291 \\
312 \\
---\end{array}$ & $\begin{array}{c}100 \\
--- \\
---\end{array}$ & $\begin{array}{l}559.12 \\
558.54 \\
558.30 \\
\end{array}$ \\
\hline Voltage gain & ---- & 0.99 & 1 & 1 & --- & --- & 1 & 1 \\
\hline DC current range & $\mathrm{mA}$ & --- & \pm 0.008 & \pm 1 & --- & --- & \pm 0.1 & \pm 0.35 \\
\hline Current offset & $\mathrm{nA}$ & --- & $<3$ & ---- & --- & --- & & 6.02 \\
\hline $\begin{array}{l}\text { Bandwidth of current } \\
\text { transfer gain }\end{array}$ & $\mathrm{MHz}$ & 605.86 & 27 & 85 & 80 & 513 & 100 & 562.85 \\
\hline Current gain & --- & 0.99 & 1 & 1 & -- & -- & 1 & 1 \\
\hline $\begin{array}{l}\text { Node } \mathrm{X} \text { parasitic } \\
\text { impedance: } \mathrm{R}_{\mathrm{X}} / \mathrm{L}_{\mathrm{X}}\end{array}$ & $\Omega / \mu \mathrm{H}$ & $150.2 / 4.16$ & $1600 / 270$ & 9/--- & 600/-- & $3 / 1.8$ & $\begin{array}{c}1-12 \mathrm{k} \\
(0.1- \\
100 \mu \mathrm{A})\end{array}$ & $\begin{array}{c}6.36 / 237 \\
9\end{array}$ \\
\hline $\begin{array}{l}\text { Node } \mathrm{Z} \quad \text { parasitic } \\
\text { impedance: } \mathrm{R}_{\mathrm{Z}} / \mathrm{C}_{\mathrm{Z}}\end{array}$ & $\begin{array}{c}\mathrm{M} \Omega / \mathrm{p} \\
\mathrm{F}\end{array}$ & $5.03 / 24$ & $\begin{array}{c}10.38 / 0.1 \\
3\end{array}$ & ----- & $\begin{array}{c}0.014 /- \\
-\end{array}$ & $\begin{array}{c}0.2510^{-3}, \\
50\end{array}$ & --- & $6.23 / 31.5$ \\
\hline $\begin{array}{l}\text { Node } \mathrm{Y}_{1}, \quad \mathrm{Y}_{2}, \quad \mathrm{Y}_{3} \\
\text { parasitic impedances: } \\
\mathrm{R}_{\mathrm{Y}} / \mathrm{C}_{\mathrm{Y}}\end{array}$ & $\mathrm{G} \Omega / \mathrm{fF}$ & $\begin{array}{c}29.0810^{3} / 3.8 \\
6 \\
--- \\
---\end{array}$ & $\begin{array}{l}130 / 5 \\
119 / 5 \\
119 / 5\end{array}$ & $\begin{array}{l}-- \\
--- \\
---\end{array}$ & $\begin{array}{l}-- \\
--- \\
---\end{array}$ & $\begin{array}{c}\infty / 15.5 \\
\infty / 21.5 \\
---\end{array}$ & $\begin{array}{l}-- \\
--- \\
--\end{array}$ & $\begin{array}{c}\infty / 12.4 \\
\infty / 12.51 \\
\infty / 12.68\end{array}$ \\
\hline Power consumption & $\mu \mathrm{W}$ & 462 & 18.6 & 1740 & 2000 & 930 & 1350 & 472 \\
\hline
\end{tabular}

If only parasitic impedances of DDCC are considered into account, the expression (35) is become as:

$$
V_{\text {OUT }}=\frac{R_{Z} / / R_{2}}{R_{1}+R_{X}} \frac{1}{1+s C_{Z}\left(R_{Z} / / R_{2}\right)}\left(V_{I N 1}-V_{I N 2}\right)
$$

where, the gain $\mathrm{A}_{\mathrm{V}}$ of instrumentation amplifier as well as the bandwidth $\omega_{c}$, where it equal to infinity in the ideal case, are given respectively by:

$$
\begin{gathered}
A_{V}=\frac{R_{Z} / / R_{2}}{R_{1}+R_{X}} \\
\omega_{c}=\frac{1}{C_{Z}\left(R_{Z} / / R_{2}\right)}
\end{gathered}
$$

In the order to make the gain of proposed VMIA controllable, the passive grounded resistances $R_{1}$ and $R_{2}$ are replaced by two active resistances structure based on MOS transistors, as shown in Fig 13.

The active resistance circuit is composed by a mixed translinear loop (M1, M2, M3, M4), two current mirrors (M5, M6 and M7, M8, M9), two current sources (M10, M12) and a bias current I0 [29]. Assuming that all transistors are operated in saturation region, the relationship between current IR and voltage $\mathrm{V}_{\mathrm{R}}$ is given by:

$$
\frac{V_{R}}{I_{R}}=R=\frac{1}{\sqrt{2 I_{0} C_{o x}}\left(\sqrt{\mu_{p}\left(\frac{W}{L}\right)_{M 4}}+\sqrt{\mu_{p}\left(\frac{W}{L}\right)_{M 2}}\right)}
$$

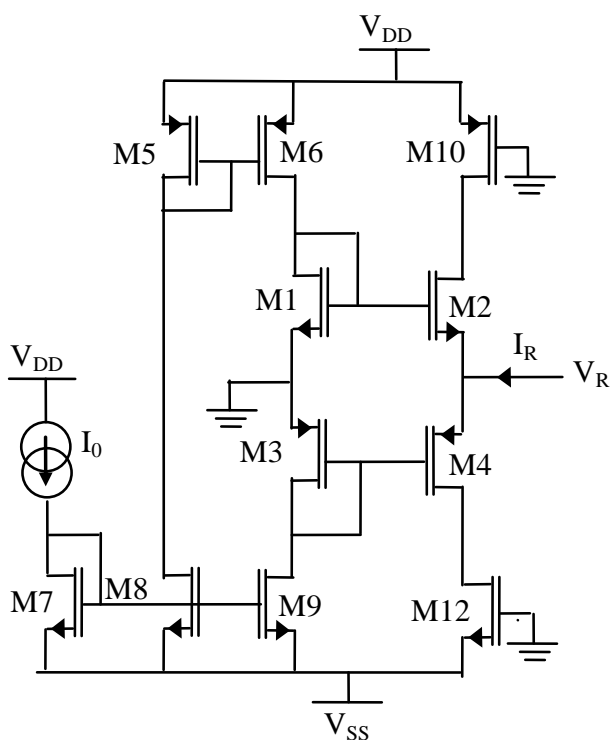

Fig 13. Active resistance controlled by bias current $\mathrm{I}_{0}$

In the above equation, the resistance variation is inversely proportional to the variation of bias current I0. To confirm this result, the active resistance circuit is simulated by $\pm 0.8 \mathrm{~V}$ supply voltage and the aspect ratios (W/L) of the MOS transistors were taken as $30 \mu \mathrm{m} / 0.18 \mu \mathrm{m}$ for M1-M2, 60 $\mu \mathrm{m} / 0.18 \mu \mathrm{m}$ for M3-M4, $0.27 \mu \mathrm{m} / 0.18 \mu \mathrm{m}$ for M7-M9 and $10 \mu \mathrm{m} / 0.18 \mu \mathrm{m}$ for M5-M6. Fig. 14 shows the variation of the resistance as a function of the bias current I0. 


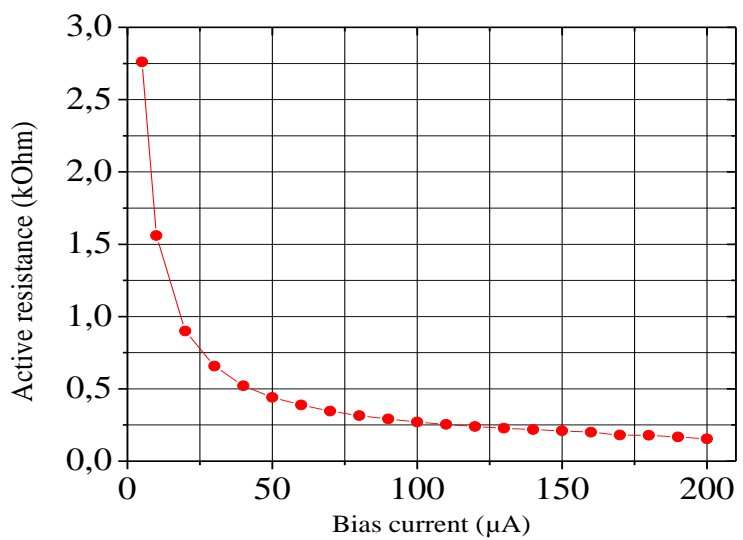

Fig 14. Variation of active resistor and center frequency values according by bias current $\mathrm{I}_{0}$

The proposed instrumentation amplifier is simulated for differential voltage gain by fixed the bias current of resistance $\mathrm{R} 2$ to $5 \mu \mathrm{A}$ and varied the bias current of resistance $\mathrm{R}_{1}$ by $5 \mu \mathrm{A}, 10 \mu \mathrm{A}, 20 \mu \mathrm{A}, 40 \mu \mathrm{A}, 60 \mu \mathrm{A}, 80 \mu \mathrm{A}$, and $100 \mu \mathrm{A}$, respectively. The variation of the differential gains as a function of frequency is shown in Fig. 15. It is clear that the simulated gains are equal to $0 \mathrm{~dB}, 4.95 \mathrm{~dB}, 9.73 \mathrm{~dB}, 12.46$ $\mathrm{dB}, 15.01 \mathrm{~dB}, 17.67 \mathrm{~dB}$ and $19.15 \mathrm{~dB}$, respectively. Also, these variations have a wide bandwidth equal to $83 \mathrm{MHz}$ and independent to gain variations.

Fig. 16 displays the DC gain of the instrumentation amplifier where a bias current of transistor R1 fixed to $100 \mu \mathrm{A}$ and the bias current of resistance $\mathrm{R} 2$ varied of $40 \mu \mathrm{A}, 60 \mu \mathrm{A}$, $80 \mu \mathrm{A}$ and $100 \mu \mathrm{A}$.

The CMRR frequency response is shown in Fig. 17. In this figure, we see that the CMRR has a high value equal to $146 \mathrm{~dB}$ for low frequency at $100 \mathrm{kHz}$.

To observe the incompatibility of active resistance on the instrumentation amplifier's gain, a Monte-Carlo analysis is performed by selecting the bias current values of two resistances $R_{1}$ and $R_{2}$ to $100 \mu \mathrm{A}$ with a $10 \%$ Gaussian deviation for 100 simulation runs. The statistical result in histogram is shown in Fig. 18 where the maximum, median and minimum numbers of circuit were found as $1,0.98$ and 0.97 , respectively.

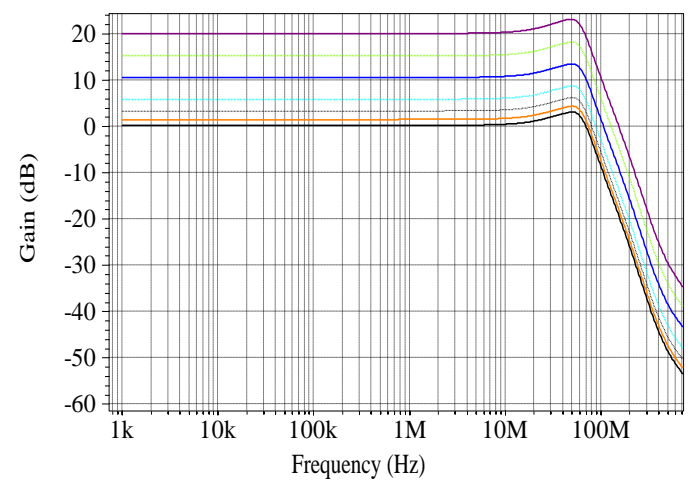

Fig. 15. Magnitude frequency response of VMIA

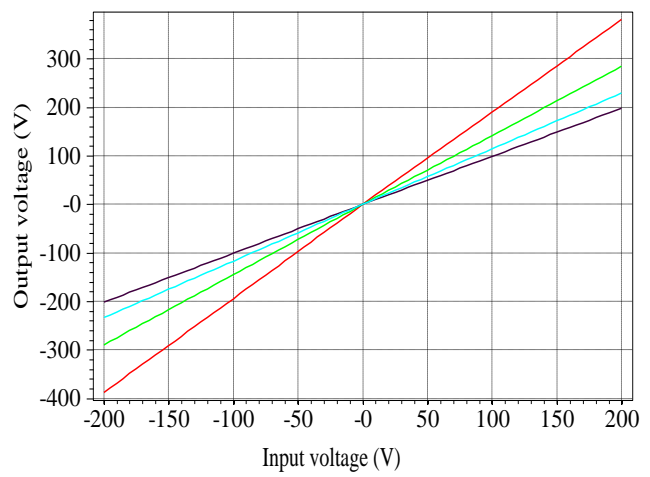

Fig. 16. DC transfer characteristics of VMIA

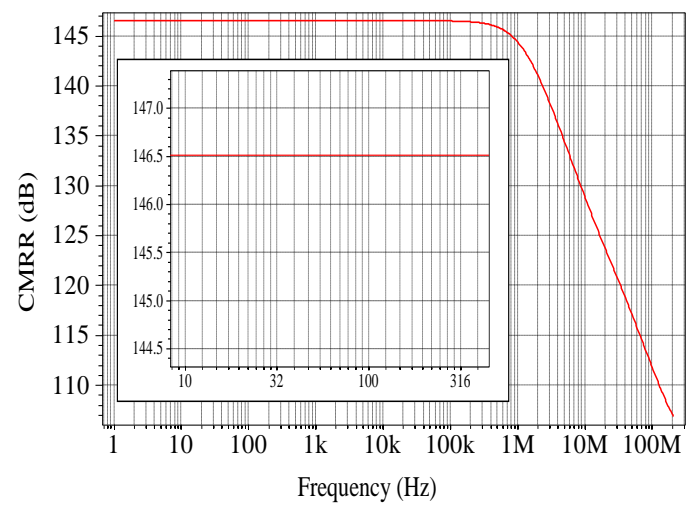

Fig. 17. CMRR frequency response of VMIA

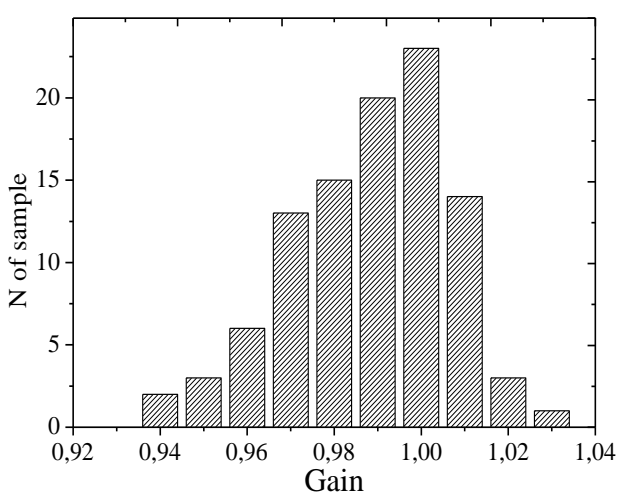

Fig. 18. Statistical results of Monte-Carlo analysis for VMIA with $10 \%$ deviation bias current $\mathrm{I}_{0}$

A comparison between the proposed circuit and others structures of instrumentation amplifiers presented in the literature is given in Table 3. Our amplifier has remarkable advantages over other circuits at the wide bandwidth, and the low supply voltage while maintaining a simple structure and a current controlled gain. Also the CMRR of the proposed circuit is higher than those of [30] but it is smaller than those of [31] while keeping a low consumption power.

\section{V.CONCLUSION}

A new CMOS realization for differential difference current conveyor circuit DDCC has presented in this paper. By using adaptive biasing circuit instead of use simple the constant bias current source, this circuit is characterized by large voltage 
Table 3. Comparison between proposed instrumentation amplifier and others presented in the literature

\begin{tabular}{|c|c|c|c|c|c|c|c|}
\hline Ref & $\begin{array}{c}\text { Technology } \\
\text { CMOS }\end{array}$ & $\begin{array}{c}\text { Supply } \\
\text { voltage }(\mathrm{V})\end{array}$ & $\begin{array}{c}\text { Bandwidth } \\
(\mathrm{MHz})\end{array}$ & $\begin{array}{c}\text { CMRR } \\
(\mathrm{dB})\end{array}$ & $\begin{array}{c}\text { Power consumption } \\
(\mathrm{mW})\end{array}$ & $\begin{array}{c}\text { Nr. of active } \\
\text { devises }\end{array}$ & $\begin{array}{c}\text { Passive } \\
\text { component }\end{array}$ \\
\hline$[30]$ & $0.35 \mu \mathrm{m}$ TSMC & \pm 3.3 & 70 & 142 & 0.519 & 2 CCCII & No \\
\hline$[31]$ & $0.35 \mu \mathrm{m}$ TSMC & \pm 0.75 & 90 & 200 & 3.5 & 3 CCCII & Yes \\
\hline$[32]$ & $0.25 \mu \mathrm{m}$ TSMC & \pm 1.5 & 8 & --- & 1.74 & 1 DVCC & Yes \\
\hline$[33]$ & $1.5 \mu \mathrm{m}$ AMS & \pm 2.5 & 0.11 & 150 & --- & 3 OPA & Yes \\
\hline $\begin{array}{c}\text { Proposed } \\
\text { IA }\end{array}$ & $0.18 \mu \mathrm{m}$ TSMC & \pm 0.8 & 83 & 146 & 0.492 & 1 DDCC & No \\
\hline
\end{tabular}

mode and current mode dynamic ranges about $\pm 0.62 \mathrm{~V}$ and \pm $0.35 \mathrm{~mA}$ respectively with low parasitic resistance $\mathrm{RX}(6.86$ $\Omega)$. The frequency responses of DDCC circuit show cut-off frequencies around $560 \mathrm{MHz}$ with unity gain. The power consumption of circuit is about $472 \mu \mathrm{W}$.

As application, a voltage mode instrumentation amplifier circuit composed by one DDCC circuit and two grounded active resistances has proposed. This VMIA circuit is characterized by controllable gain, wide bandwidth $(83 \mathrm{MHz})$, a high common-mode rejection ratio (CMRR) about $146 \mathrm{~dB}$ for different values of gain.

The simulation results of proposed controlled VMIA are verified with TSPICE using $0.18 \mu \mathrm{m}$ TSMC CMOS technology. It has a good accuracy with the theoretical results where the power consumption is about $0.492 \mathrm{~mW}$

\section{References}

[1] M.N. Anas, A.N. Norali, W. Jun, "On-line monitoring and analysis of bioelectrical signals," Procedia computer science, 42, 365-371, 2014.

[2] Panagiotis C. Petrantonakis, Leontios J. Hadjileontiadis, "A novel emotion elicitation index using frontal brain asymmetry for enhanced EEG-based emotion recognition," IEEE Transactions On Information Technology In Biomedicine, 15 (5), 737-746, 2011.

[3] S. Patel, H. Park, P. Bonato, L. Chan, M. Rodgers, "A review of wearable sensors and systems with application in rehabilitation", Journal of NeuroEngineering and Rehabilitation, 9 (21), 1-17, 2012.

[4] Aisha A. Alhammadi, Tasnim B. Nazzal, Soliman A. Mahmoud, "A CMOS EEG detection system with a configurable analog frontend architecture," Analog integrated circuits and signal processing, 89 (1), 151-176, 2016.

[5] C. Augusto Prior, C. Ramos Rodrigues, A. Luiz Aita, J. B. dos Santos Martins, F. Vieira, "Design of an integrated low power high CMRR instrumentation amplifier for biomedical applications," Analog integrated circuits and signal processing, 57 (1-2), 11-17, 2008.

[6] W. Bai, Zhangming Zhu, "A 0.5-V power-efficient low-noise CMOS instrumentation amplifier for wireless biosensor", Microelectronics Journal, 51, 30-37, 2016.

[7] Y. Tseng, Yingchieh Ho, S. Kao, and C. Su, "A 0.09 W low power front-end biopotential amplifier for biosignal recording," IEEE transactions on biomedical circuits and systems, 6 (5), 508 - 516, 2012.

[8] W. J. Su, F. J. Lidgey, "Common-mode rejection ratio in current-mode instrumentation amplifiers," Analog integrated circuits and signal processing, 7 (3), 257-260, 1995.

[9] E. Yuce, "Various current-mode and voltage-mode instrumentation amplifier topologies suitable for integration," Journal of circuits, systems and computers, 19 (3), 689-699, 2010.

[10] A. Voulkidou, S. Siskos, T. Laopoulos, "Analysis and design of a chopped current mode instrumentation amplifier," International journal of microelectronics and computer sciences, 4 (1), 6-11, 2013.

[11] G. Zamora-Mejía, J. Martínez-Castillo, J. Miguel, R. Pérez, Alejandro D.Sánchez, "A current mode instrumentation amplifier based on the flipped voltage follower in $0.50 \mu \mathrm{m}$ CMOS," Analog integrated circuits and signal processing, 87 (3), 389-398, 2016.
[12] S. Baswa, A. J. Lopez-Martın, R. G. Carvajal, J. Ramırez-Angulo, "Low-voltage power-efficient adaptive biasing for CMOS amplifiers and buffers," Electronics letters, 40 (4), 217 - 219, 2004.

[13] A. J. López-Martín, S. Baswa, Jaime Ramirez-Angulo, Ramón González Carvajal, "Low-voltage super class AB CMOS OTA cells with very high slew rate and power efficiency," IEEE Journal of solid-state circuits, 40 (5), 1068 - 1077, 2005

[14] T. Ettaghzouti, N. Hassen, K. Besbes, "A novel low-voltage low-power CCII based on super class AB CMOS OTA cells and filter application," International multi-conference on systems signals and devices, 1-6, 2015.

[15] H. Bdiri Gabbouj, N. Hassen, K. Besbes, "Low Voltage high gain linear class ab cmos ota with dc level input stage," International journal of electrical, computer, energetic, electronic and communication engineering, 5 (8), 1022- 1028, 2011

[16] M. Jimenez-Fuentes, R. G. Carvajal, L. Acosta, C. Rubia-Marcos, A. Lopez-Martın, J. Ramirez-Angulo, "A tunable highly linear CMOS transconductor with $80 \mathrm{~dB}$ of SFDR, Integration," the VLSI journal, 42 (3), 277-285, 2009

[17] R. González Carvajal, J. Ramírez-Angulo, A. J. López-Martín, A. Torralba, Juan Antonio G. Galán, Alfonso Carlosena, Fernando Muñoz Chavero, "The flipped voltage follower: a useful cell for low-voltage low-power circuit design," IEEE transactions on circuits and systems 52 (7), 1276- 1291, 2005.

[18] U. Singh, Maneesha Gupta, "High frequency flipped voltage follower with improved performance and its application," Microelectronics Journal, 44, 1175-1192, 2013

[19] C. Muñiz-Montero, L.A. Sánchez-Gaspariano, J.J. Camacho-Escoto, L.A. Villa-Vargas, H. Molina-Lozano, J.E. "Molinar-Solís, A $90 \mu \mathrm{m} \times$ $64 \mu \mathrm{m} 225 \mu \mathrm{W}$ class-AB CMOS differential flipped voltage follower with output driving capability up to $100 \mathrm{pF}$," Microelectronics Journal, 44 (10), 930-940, 2013

[20] W. Chiu, S. I. Liu, H. W. Tsao, J. J. Chen, CMOS differential difference current conveyor and their applications, IEE Proceedings-Circuits Devices Systems, 143, 91-96, 1996.

[21] T. Ettaghzouti, N. Hassen, K. Garradhi, K Besbes, "Wide bandwidth CMOS four-quadrant mixed mode analogue multiplier using a second generation current conveyor circuit," Turkish journal of electrical engineering \& computer sciences, 1708-179, 2018.

[22] N. Hassen, T. Ettaghzouti, K. Garradhi, K. Besbes, "MISO current mode bi-quadratic filter employing high performance inverting second generation current conveyor circuit," International journal of electronics and communications, 2017.

[23] H. Chen, "Tunable versatile current-mode universal filter based on plustype DVCCs," International journal of electronics and communications, 66, 332-339, 2012.

[24] A.P. Naik, N.M. Devashrayee, "Characterization of a CMOS differential current conveyor using $0.25 \mu \mathrm{m}$ technology," International journal of advanced Engineering and applications, 177-182, 2010.

[25] T.M. Hassan, S.A. Mahmoud, "New CMOS DVCC realization and applications to instrumentation amplifier and active-RC filters," International journalof electronics and communications, 64(1), 47-55, 2010

[26] F. Khateb, M. Kumngern, V. Spyridon, C. Psychalinos, "Differential Difference Current Conveyor Using Bulk-Driven Technique for UltraLow-Voltage Applications," Circuits, Systems, and Signal Processing, 33 (1), 159-176, 2013

[27] M. A. Ibrahim, E. Yuce, S. Minaei, "A new DVCC-based fully cascadable voltage-mode full-wave rectifier, Journal of computational electronics,", 15 (4), 1440-1449, 2016. 
[28] P. Prommee, M. Somdunyakanok, "CMOS-based current-controlled DDCC and its applications to capacitance multiplier and universal filter," International journal of electronics and communications, 65 (1), $1-8,2011$.

[29] T. Ettaghzouti, N. Hassen, K. Besbes, "High frequency controlled universal current mode filter using second generation conveyor CCII", International journal of advances in computer and electronics engineering, 2 (3), 11-16, 2017.

[30] H. Ercan, S. A. Tekin, M. Alci, "Voltage- and current-controlled high CMRR instrumentation amplifier using CMOS current conveyors," Turkish journal of electrical engineering and computer sciences, 20 (4), 547- 556, 2012.

[31] Z. M'harzi, M. Alami, F. Temcamani, "Low voltage, high CMRR, and wide bandwidth novel current mode current controlled instrumentation amplifier," Analog integrated circuits and signal processing, 90 (1), 199-205, 2016.

[32] T. M. Hassan, S. A. Mahmoud, "New CMOS DVCC realization and applications to instrumentation amplifier and active-RC filters," International journal of electronics and communications, 64 (1), 47-55, 2010.

[33] C.A. Prior, C.R. Rodrigues, A.L. Aita, J.B.S. Martins, F.C.B. Vieira, "Design of an integrated low power high CMRR instrumentation amplifier for biomedical applications", Analog Integrated Circuit Signal Processing, 57, 11-17, 2008.

\section{Creative Commons Attribution License 4.0 (Attribution 4.0 International, CC BY 4.0)}

This article is published under the terms of the Creative Commons Attribution License 4.0

https://creativecommons.org/licenses/by/4.0/deed.en_US 